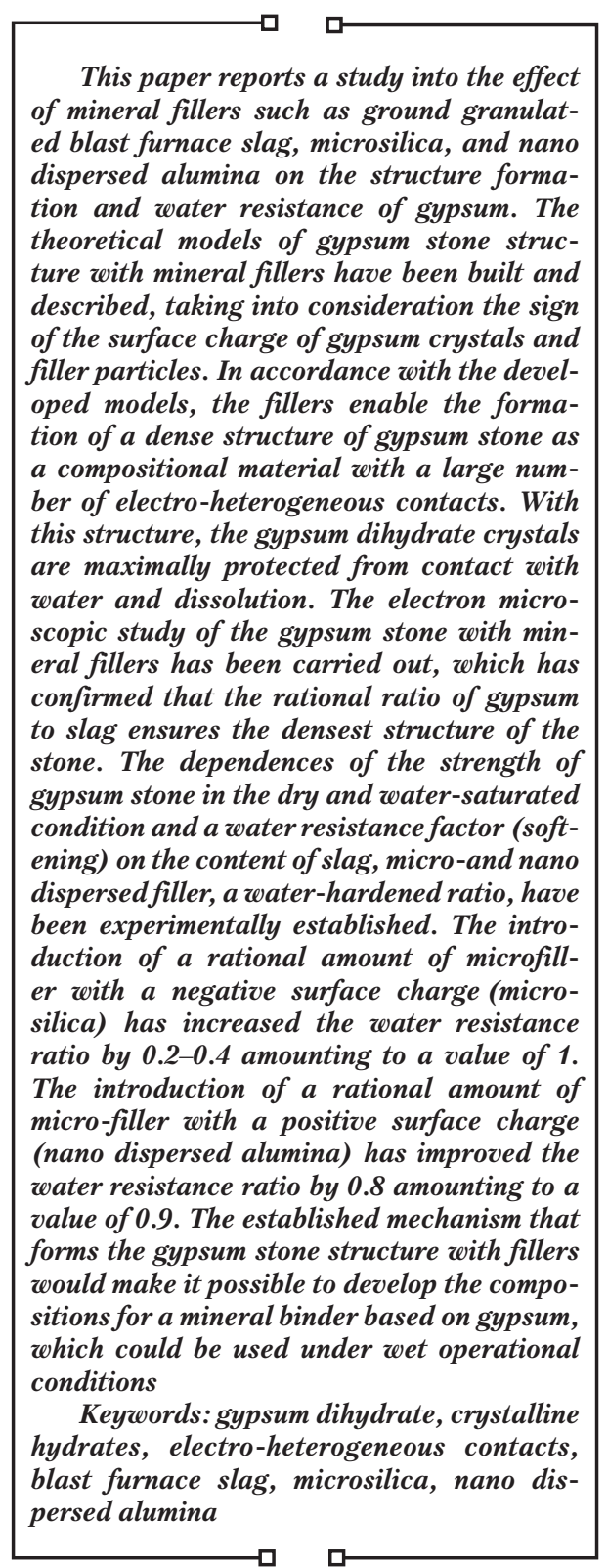

Received date 28.10.2020

Accepted date 29.01.2021

Published date 10.02.2021
UDC 691.533

DOI: $10.15587 / 1729-4061.2021 .224221$

\section{ESTABLISHING PATTERNS IN THE INFLUENCE OF MICRO- AND NANO-DISPERSED MINERAL ADDITIVES ON THE WATER RESISTANCE OF CONSTRUCTION GYPSUM}

A. PIugin

Doctor of Technical Sciences, Professor, Head of Department Department of Railway Track and Transport Structures**

E-mail: aaplugin@gmail.com

A. I e fimenko

Postgraduate Student*

E-mail: a.efimenko03@gmail.com

0. B orziak

$\mathrm{PhD}$, Associate Professor* E-mail: borziak.olga@gmail.com

E. G e vork y a n

Doctor of Technical Sciences, Professor Department of Quality, Standardization, Certification and Manufacturing Technology of Products**

E-mail: gev@kart.edu.ua

O. P I u h i n

$\mathrm{PhD}$, Associate Professor Department of Structural Mechanics and Hydraulics** E-mail: plugin0785@gmail.com *Department of Building Materials and Structures** **Ukrainian State University of Railway Transport Feierbakha sq., 7, Kharkiv, Ukraine, 61050

Copyright (C 2021. A. Plugin, A. Iefimenko, O. Borziak, E. Gevorkyan, O. Pluhin This is an open access article under the CC BY license (http://creativecommons.org/licenses/by/4.0)

\section{Introduction}

Gypsum-based materials are characterized as environmentally friendly, highly durable, strong enough [1-4]. However, low water resistance limits their use to dry operating conditions; improving it could significantly expand the application scope of gypsum materials. Low water resistance is mainly explained by the solubility of calcium sulfate dihydrate, the spreading forces created in pores by the absorbed water, etc. The water resistance of gypsum binders can be increased by reducing the water-gypsum ratio, by combining them with hydraulic binders [5-7], by introducing mineral additives-fillers [8-13], hydrophobic additives [13], polymers, fibers [14]. As revealed by the analysis of the available research results, the most effective is the introduction of mineral additives into the gypsum stone. However, the above techniques generally do not increase water resistance to more than 0.8 .

Thus, it is a relevant task to undertake research that aims to improve the water resistance and extend the application scope of gypsum materials. In this regard, it is promising to study the mechanism of the effect of mineral additives-fillers on the processes of structure formation of gypsum stone, which could increase its water resistance.

\section{Literature review and problem statement}

In [5], the water resistance of gypsum from waste is achieved by mixing it with flue ash and Portland cement. The authors of [2] introduce mineral and organic modifiers into gypsum, explaining their effectiveness by a change in 
the morphology of crystals and the strengthening at the atomic-molecular level. The authors of [3] draw similar conclusions. By studying historical gypsum solutions, they provide an interesting explanation for the high water resistance of some of them. In their opinion, the edges of gypsum crystals have different solubility and structures in which the most soluble faces are closed and the least soluble are open more water-resistant. The authors conclude that the decisive role belongs to the change in the morphology of the crystals of gypsum dihydrate due to the introduction of additives.

In [3], to form the densest structure of gypsum stone, the authors use computer simulation methods for the composition of the raw mixture; in [7], the authors justify the optimal proportion, which ensures the maximum strength of the mixed binder from slag, gypsum, and clinker.

In [6], the increase in the strength of gypsum is explained by the ordering of the structure through the introduction of the mineral additives of quartz, diopside, glass, limestone.

The introduction of $14 \%$ of ultra-dispersed zeolite into gypsum increased its water resistance from 0.31 to 0.84 in [8]. A similar effect of the introduction of zeolite and carboxylate is explained in [11] by a significant change in the structure. In [14], the increase in the gypsum strength is explained by the effect of dispersed reinforcement.

The authors of [9] modify gypsum with metallurgical dust and multi-wall carbon nanotubes. They explain the observed increase in water resistance by the formation of amorphous hydro silicate structures on the surface of gypsum crystals, which bind gypsum crystals and prevent water from accessing them.

The gypsum is modified with ultra-dispersed metallurgical dust and anhydrite in [10]. The authors do not detect the acceleration of hydration or its new products but note a change in their morphology, leading to the compaction and increased strength and water resistance. However, as noted in [12], as a result of the introduction of a complex chemical supplement, the hydration was accelerated and a denser structure was formed.

The SiC silicon carbide micro- and nano-additives that act, in the opinion of the authors of [13] as crystallization centers, also accelerate the hydration and structure formation, leading to the formation of larger crystals.

Papers $[15,16]$ show that the properties of mineral binder materials, including their water resistance, are predetermined by the electrostatic interactions between the hydration products' particles, fillers through double electrical layers on their surface. The high strength and water resistance of hydraulic binders are determined by strong electro-heterogeneous contacts between particles with the opposite surface charge, in which the electrostatic attraction operates. The hypothesis that solid mineral binders achieved the maximum possible physical and mechanical indicators as a result of interaction between the active surface centers of the compositional silicate materials in the contacts between them has been put forward and confirmed in [17]. According to this hypothesis, the maximum indicators are provided by the equality of the total surface areas of the particulates of the dispersed phase per volume unit, which have opposite surface charges.

Studies [15-17] are theoretical; the research reported in them applies exclusively to hydraulic binders. Air binders consist of particles with the same surface charges, so their lesser strength and, especially, water resistance is caused by weak electro-homogenous contacts, in which there are both intermolecular attraction and electrostatic repulsion. Thus, there remains an unresolved issue related to forming in the air binders of electro-heterogeneous contacts, whose maximum number is possible when the total areas of the surface of particles with the opposite surface charge are equal. We believe that achieving this equality is possible by adjusting the composition of binder hydration products and introducing highly dispersive inert particles into their structure. This can be achieved by the introduction of mineral and chemical additives, mixing several types of binders, etc.

It is known [18-23] that mineral and chemical additives increase strength, improve other physical-mechanical and hydro-physical characteristics of materials based on mineral binders.

By studying the effects of additives, different authors give different explanations for the reasons to improve these characteristics. The introduction of highly-dispersed chalk, according to the authors of [18], leads to a change in the composition and structure of the Portland cement hydration products and a decrease in the permeability of concrete for aggressive substances. An integrated mineral additive, which includes granulated blast furnace slag, fly ash, and pozzolana (zeolite), according to [19], ensures the compaction of the cement stone structure, the increased strength. In [20], due to the introduction of Portland cement clinker into the slag-alkaline binder, control over the natural deformations of the artificial stone is achieved. The authors of [21], by modifying the binder substances with clay fillers, take into consideration the acid-basic properties of their surface and associate the observed effects with them. Electrolytes, especially in the form of an integrated additive, provide for an increase in the water resistance [22] and strength [23] of cement composites. in [23], this effect of potassium and sodium sulfates and carbonates is explained by the modification of the microstructure and the porous structure.

Our analysis of the above studies makes it possible to predict similar processes in air binders such as gypsum. Adjusting the structure and properties of gypsum materials is also possible due to the introduction of mineral fillers and other binders of different composition and degree of dispersion.

All the studies analyzed confirm the effectiveness of the use of mineral and chemical additives to improve the physical and mechanical properties of gypsum stone. However, all those works do not take into consideration the electrosurface properties of structure-forming elements, which are decisive in the formation of a stable structure of gypsum stone. These properties are taken into consideration in paper [24], which recommends the introduction of fillers and micro-fillers with certain electrosurface charges into gypsum to create strong and water-resistant electro-heterogeneous contacts. The authors of [24] developed conditional (idealized) schemes (models) of gypsum structures with fillers (Fig. 1). They substantiated the increase in the strength and water resistance of gypsum by the introduction of filler whose particles have a negative surface charge and whose average size is larger than the average size of gypsum crystals. Ground granulated blast furnace slag can serve such a filler. To protect the end faces of the gypsum dihydrate crystals from dissolution, it is proposed to introduce micro-fillers, which also have a negative surface charge and whose average particle size is not larger than 0.2 of the average size of filler particles (Fig. 1,b). 


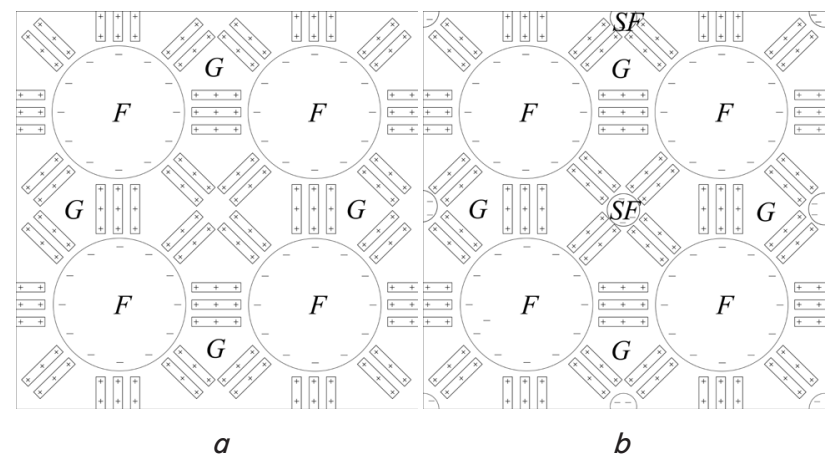

Fig. 1. Schematic of the structure of gypsum stone $G$ : $a-$ with filler $F ; b-$ with filler $F$ and micro-filler $S F[24]$

However, the study of the crystalline structure of the gypsum dihydrate made it possible to establish in [25] that the edges of its crystals have a different sign of the surface charge (the equilibrium electrosurface potential). The signs of the surface charges of dispersed particles in water-disperse systems, including solidifying mineral binders, were estimated using a calculation-experimental method to determine the absolute and equilibrium electrosurface potential [15], experimental methods for determining the electro-kinetic potential [26], separation in a high-voltage electric field [27], as well as the absorption of color indicators $[21,27]$. The longitudinal faces have a positive surface charge, the end faces - negative. This is confirmed by the well-known tendency of gypsum to the formation of spherulites and dendrites (Fig. 2, $a$ ) during hydration, in which the electro-heterogeneous contact between the longitudinal and transverse edges of the dihydrate crystals is implemented. Given this, the schemes in Fig. 1 do not fully explain the mechanism of influence of mineral fillers and micro-fillers on the formation of gypsum stone structure. In addition, the introduction of mineral fillers only with a negative surface charge and the formation of a structure corresponding to these conditional schemes, would not provide for sufficient water resistance of gypsum. Those studies can be advanced when taking into consideration the features of the crystalline structure of gypsum and investigating the effect exerted on the processes of structural formation by mineral fillers with different electrosurface properties and varying degrees of dispersion.

Our analysis of the literary data suggests that it is appropriate to conduct a study of the processes of structure formation of gypsum stone with mineral additives taking into consideration the electrosurface properties of all components and the electrosurface anisotropy of gypsum crystalline hydrates.

Thus, the unresolved issue is revealing the mechanism of influence of mineral fillers and their electrosurface properties on the structural formation of gypsum stone, which could significantly improve its water resistance.

\section{The aim and objectives of the study}

The aim of this study is to reveal the mechanism of influence of mineral fillers such as ground granulated blast furnace slag, microsilica, and nano dispersed alumina on the structural formation of gypsum stone, accounting of which could significantly improve its water resistance.

To accomplish the aim, the following tasks have been set:

- to theoretically study the mechanism of the effect of mineral additives on the structure formation of gypsum stone by modeling its structure taking into consideration the sign of the surface charge of the particles forming the structure; to conduct an electron microscopic study to confirm the results from the theoretical investigation;

- to experimentally investigate the dependences of gypsum stone strength in dry and water-saturated conditions and a water resistance factor on the content of mineral additives.

\section{Materials and methods to study the effect of mineral additives on gypsum water resistance}

In the experimental study, we used gypsum for construction, brands G-4, G-7 (Fig. 2,a); the ground granulated blast furnace slag from "Zaporizstal" and "Azovstal"; microsilica, nano dispersed alumina, plasticizing additive based on sodium lignosulfonate.

Ground granulated blast furnace slag from "Zaporizhstal" (Fig. 2, b): chemical composition, \%: $\mathrm{SiO}_{2}-36.5$; $\mathrm{Fe}_{2} \mathrm{O}_{3}-5.1 ; \mathrm{Al}_{2} \mathrm{O}_{3}-6.7 ; \mathrm{CaO}-46.5 ; \mathrm{MgO}-5.9 ; \mathrm{SO}_{3}-4.2 ;$ basicity module, 1.19 ; true density, $2,810 \mathrm{~kg} / \mathrm{m}^{3}$; specific surface, $3,000 \mathrm{~cm}^{2} / \mathrm{g}$.

Ground granulated blast furnace slag from "Azovstal": chemical composition, \%: $\mathrm{SiO}_{2}-36.9 ; \mathrm{Al}_{2} \mathrm{O}_{3}-10.5 ; \mathrm{CaO}-$ $45.9 ; \mathrm{Fe}_{2} \mathrm{O}_{3}-5.17 ; \mathrm{MgO}-2.9 ; \mathrm{MnO}-2.07 ; \mathrm{S}-1.59$; basicity module, 1.07 .

Microsilica - the dust of gas purification from ferrosilicon production (Fig. 2, $c, d$ ): chemical composition, \%: $\mathrm{SiO}_{2}-95.6$; $\mathrm{Fe}_{2} \mathrm{O}_{3}-0.5 ; \mathrm{Al}_{2} \mathrm{O}_{3}-0.9 ; \mathrm{CaO}-0.8 ; \mathrm{MgO}-0.2 ; \mathrm{SO}_{3}-0.5 ;$ $\mathrm{Na}_{2} \mathrm{O}-0.3 ; \mathrm{K}_{2} \mathrm{O}-0.3$; granulometric composition, \%: up to $5 \mu \mathrm{m}-21 ; 5-10 \mu \mathrm{m}-14 ; 10$ to $20 \mu \mathrm{m}-9 ; 20-30 \mu \mathrm{m}-8$; $30-40 \mu \mathrm{m}-6 ; 40-50 \mu \mathrm{m}-11 ; 50-100 \mu \mathrm{m}-26$; exceeding $100 \mu \mathrm{m}-5$; true density, $2,400 \mathrm{~kg} / \mathrm{m}^{3}$.

Nano dispersed alumina: chemical composition, \%: a- $\mathrm{Al}_{2} \mathrm{O}_{3}$ - at least 99.8; $\mathrm{Si}-0.15 ; \mathrm{Fe}-0.009 ; \mathrm{Mg}-0.001$; $\mathrm{Cu}-<0.001 ; \mathrm{Na}-0.008$; particle size, 50-80 nm (Fig. 2, $d, e$ ).

The slags are dominated by silicates, which have a negative surface charge, the surface charge of the microsilica is also negative, that of the particles of nano dispersed alumina is positive [15].

We elucidated the mechanism of the effect of mineral additives on the structure formation and water resistance of gypsum in the theoretical study. The simulation of the structure of gypsum stone with mineral additives was carried out taking into consideration the sign of the surface charge of gypsum crystals, slag grains, the particles of microsilica and nano dispersed alumina.

To confirm the results of our theoretical research, the optical-microscopic and electron-microscopic studies of mineral fillers and gypsum stone structures with them were carried out. The gypsum was examined during the hydration process in an aqueous preparation; the fillers - with the help of the electron microscope JEOL JSM-840 (Japan) at a voltage of $5 \mathrm{kV}$, and in the immersion preparations, using the light microscope MBI-6 LOMO (Russia). The gypsum stone was examined on chips using the scanning electron microscope (SEM) Philips XL 30 ESEM-FEG (the Netherlands) at a voltage of $15 \mathrm{kV}$, at magnification $\times 300 ; \times 1,000 ; \times 2,000$. 


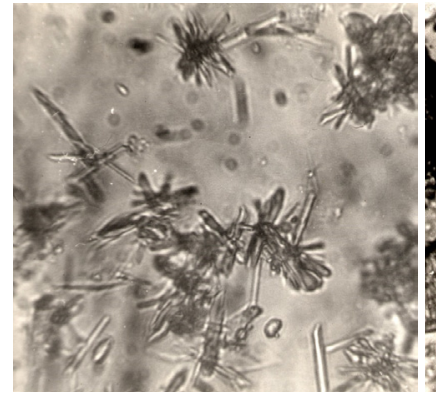

a

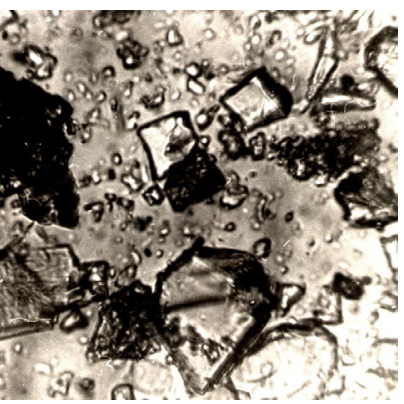

b

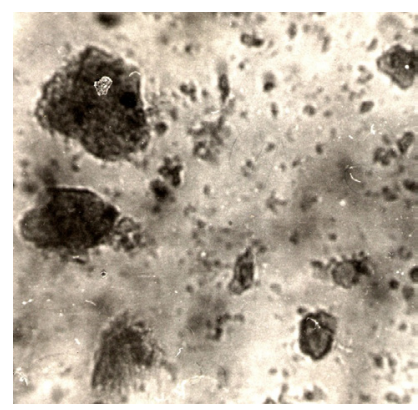

C

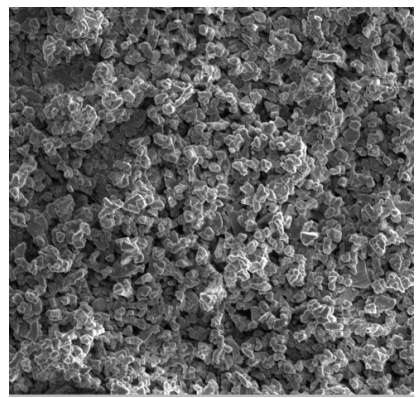

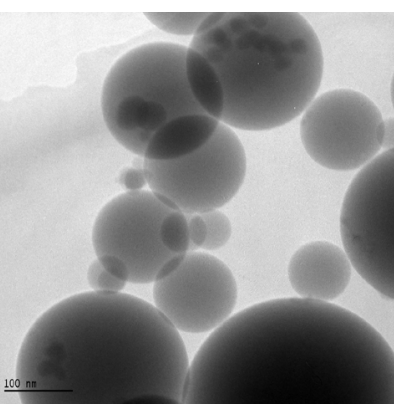

$d$

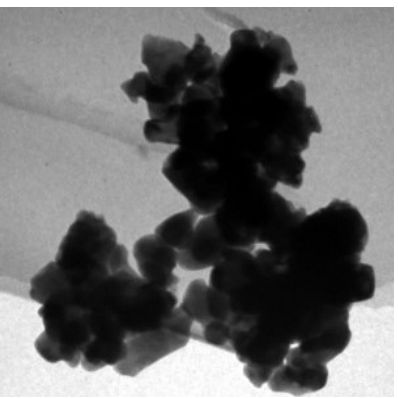

$f$

Fig. 2. Dispersed materials: $a$-gypsum after 20 minutes of hydration, light microscope, magnification $\times 225$;

$b$ - ground granulated blast furnace slag, light microscope, magnification $\times 225$;

c, $d$ - microsilica, light microscope, magnification $\times 225(c)$, SEM, $\times 10,000(d)$;

$e, f$-nano dispersed alumina, SEM, magnification $\times 2,000(e)$, magnification $\times 3,000(f)$

In addition, we experimentally investigated the dependences of the strength of gypsum stone in the dry $f$ and the water-saturated $f_{w}$ condition and the water resistance factor (softening) $K_{w}=f_{w} / f$ on the content of slag $S /(G+S)$, micro-filler $M F /(G+S)$, the water-solid ratio $W /(G+S)$. The study was carried out using prism samples measuring $160 \times 40 \times 40 \mathrm{~mm}$ and $40 \times 10 \times 10 \mathrm{~mm}$. We tested each composition and hardening aging involving: 3 pieces ( 6 halves) of the prisms measuring $160 \times 40 \times 40 \mathrm{~mm} ; 10$ pieces (20 halves) of those measuring $40 \times 10 \times 10 \mathrm{~mm}$. In each prism, one half was tested for compression in a dry state, the other half - in a state, water-saturated to constant mass. We introduced, into compositions with a water-solid ratio of less than 0.3 , a plasticizing additive based on sodium lignosulfonate in the amount of $2 \%$ of the gypsum mass.

5. Results of studying the effect of mineral additives on the structure and the physical-mechanical properties of gypsum stone

5.1. The simulation and electron microscopic examination of the structure of gypsum stone with mineral additives

New data on the sign-different surface charge of the edges of gypsum crystalline hydrates [25] have made it possible to improve the conditional schemes of gypsum structure with mineral additives shown in Fig. 1. The improved patterns of gypsum stone structure with mineral additives-fillers are demonstrated in Fig. 3. Fig. 3, $a$ illustrates a scheme of gypsum stone with a rational ratio of gypsum to filler content; Fig. 3, $b$-with a deficiency of gypsum dihydrate. The distribution of micro-filler particles would also depend on the surface charge sign, which is illustrated on the diagrams: Fig. 3, $c$-the gypsum stone containing a micro-filler with a negative surface charge, Fig. 3, $d$ - with a micro-filler with a positive surface charge.

The adequacy of the developed schemes is confirmed by the results from the electron microscopic study, which are shown in Fig. 4. We examined the surfaces of the chipped gypsum-slag stone with the relative slag content $S /(G+S)=0.4$ and the water-solid ratio $W /(G+S)=0.36$ without a micro-filler and with a micro-filler - nano dispersed alumina with the relative content $M F /(G+S)=0.02$.
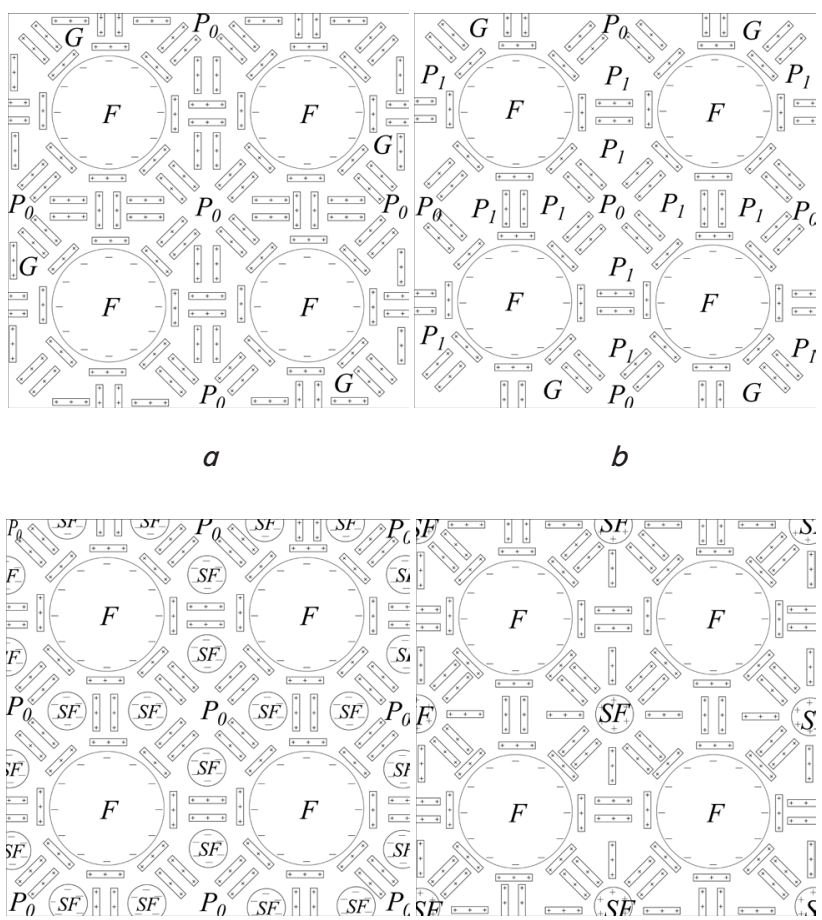

d

Fig. 3. Conditional scheme of the structure of gypsum stone $G$ with filler $F$ :

$a$ - with a rational ratio of the gypsum to filler content; $b$ - with a deficiency of gypsum dihydrate;

$c$ - with a micro-filler with a negative surface charge ( $S F-$ ); $d$-with a micro-filler with a positive surface charge $(S F+)$ 


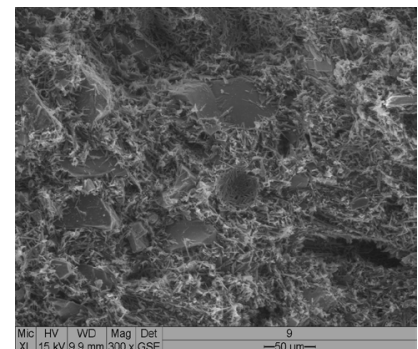

$a$

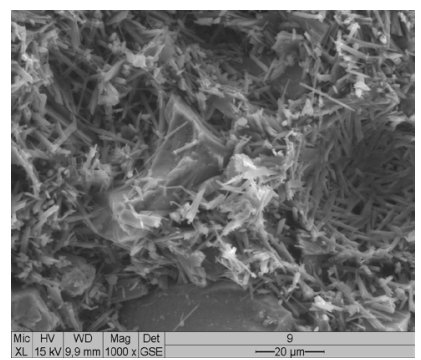

C

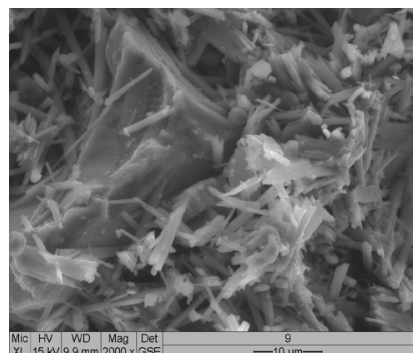

$e$

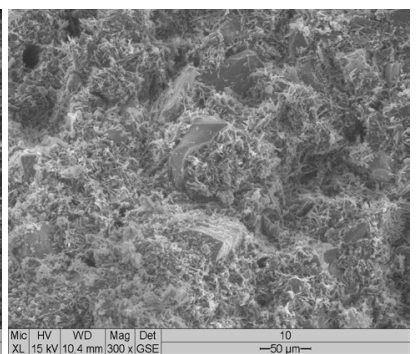

$b$

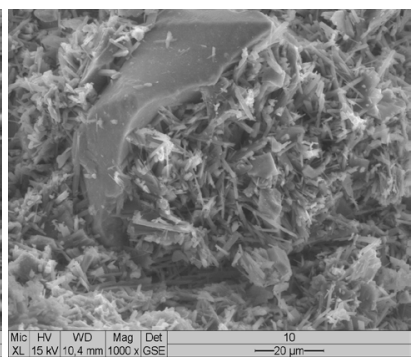

$d$

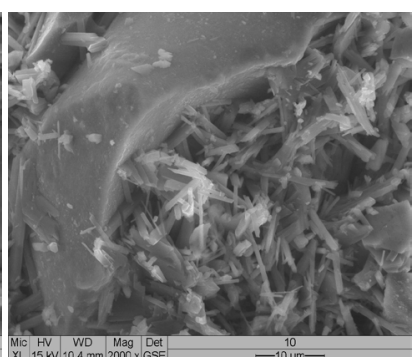

$f$
Fig. 4. Electron-microscopic images (EMI) of the surface of the chipped gypsum-slag stone, $S /(G+S)=0.4, W /(G+S)=0.36$ :

$a$ - without a micro-filler, magnification $\times 300$;

$b$ - with a micro-filler - nano dispersed alumina $M F /(G+S)=0.02$, magnification $\times 300$;

$c$ - without a micro-filler, magnification $\times 1,000$; $d$-with a micro-filler - nano dispersed alumina $M F /(G+S)=0,02$, magnification $\times 1,000$;

$e$-without a micro-filler, magnification $\times 2,000$;

$f$ - with a micro-filler - nano dispersed alumina $M F /(G+S)=0.02$; magnification $\times 2,000$

5. 2. The dependence of the strength and water resistance factor of gypsum stone on the content of mineral additives

Fig. 5, 6 show the results of studying the dependence of the strength and water resistance of gypsum-slag stone on the relative content of the mineral filler - slag $S /(G+S)$, the water-solid ratio $W /(G+S)$, and the relative content of the micro-fillers microsilica and nano dispersed alumina $M F /(G+S)$.

Fig. 5 demonstrates that the dependence of strength and water resistance on $S /(G+S)$ is extreme with highs in the slag content interval $S /(G+S)=0.24-0.4$ (Fig. 5, as well as [24]).

The charts in Fig. 6, $a, c, e$ demonstrate that with the introduction of microsilica up to 0.035 , the water resis- tance coefficient increases by $0.2-0.4$ units, from $0.5-0.6$ to $0.7-1.0$. The charts in Fig. $6, b, d$, illustrate that with the introduction of nano dispersed alumina up to 0.06 , the water resistance coefficient increases by 0.8 units, from 0.1 to 0.9 .

It is noted that with the introduction of the micro-filler, the strength of the gypsum-slag stone in a dry state does not increase, and even decreases slightly (Fig. 6, $a-d$ ). However, its strength in the water-saturated state increases, which provides an observed increase in the water resistance factor $K_{w}$.

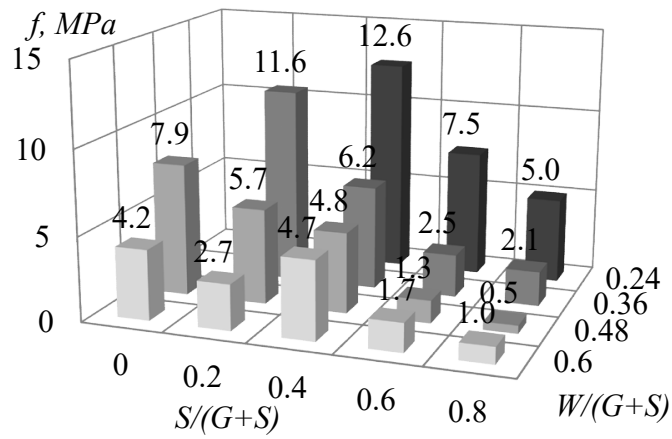

$a$

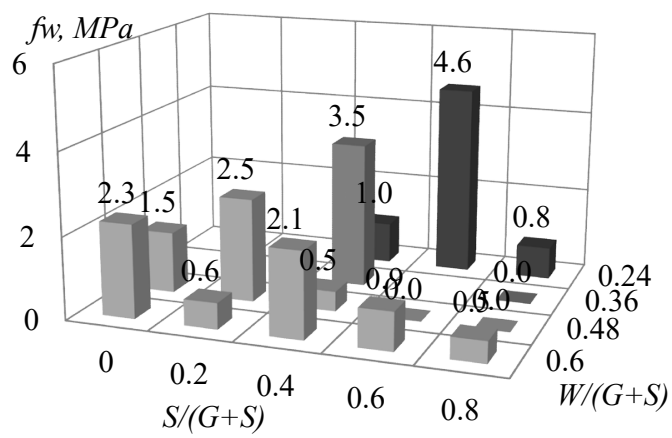

$b$

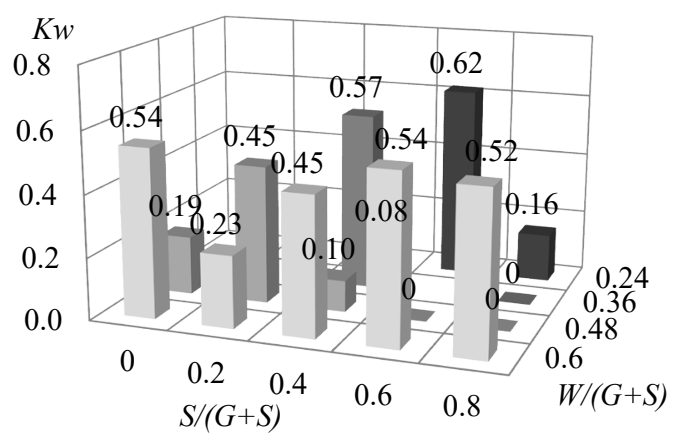

$c$

Fig. 5. The dependence of the strength and water resistance of gypsum-slag stone at the age of 7 days on the content of the filler - slag $S /(G+S)$ and water-solid ratio $W /(G+S)$ :

$a$ - the strength at compression in a dry state $f$,

$b$ - the strength at compression in a water-saturated state $f_{w}$; $c$ - water resistance ratio $K_{w}$ 


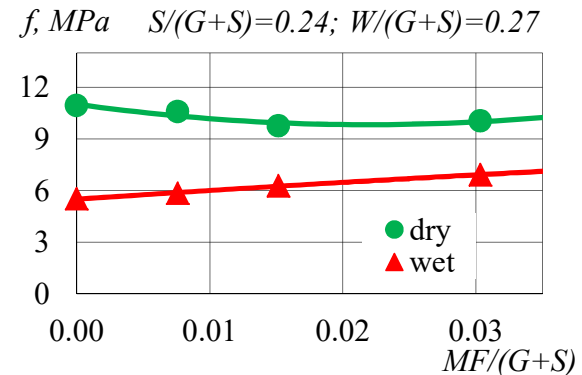

$a$

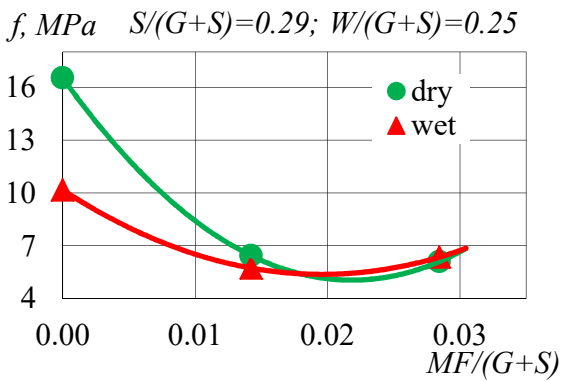

$a$

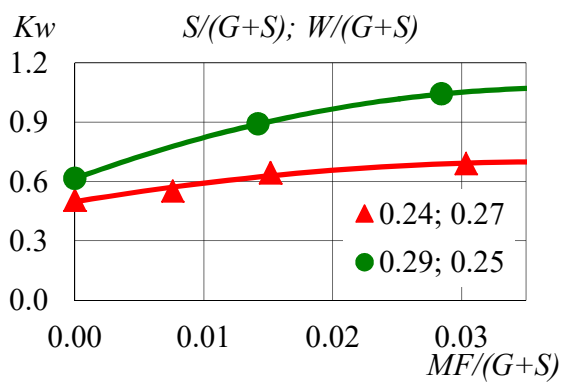

e

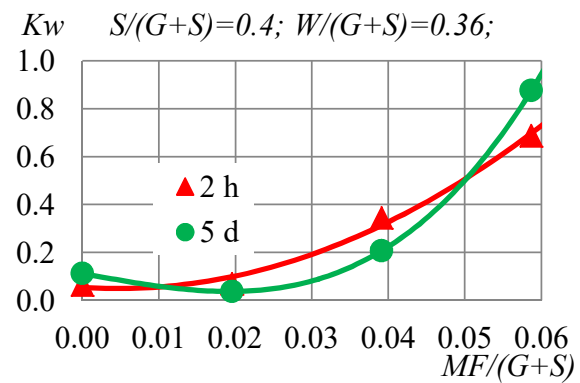

$f$

Fig. 6. The dependence of strength at compression $f$ in a dry (dry) and water-saturated (wet) condition and the water resistance ratio of gypsum-slag $K_{w}$ on the microfiller content $M F /(G+S)$ at various amounts of slag $S /(G+S)$ and water-solid ratios $W /(G+S): W /(G S): a, c, e-$ the gypsum of brand G-7, the slag from "Zaporizhstal", the micro-filler is microsilica, the age is 7 days; $b, d, f$ - the gypsum of brand $\mathrm{G}-4$, the slag from "Azovstal", the micro-filler is nano dispersed alumina, the age

is 2 hours $(b, f)$ and 5 days $(d, e)$

\section{Discussion of results of studying the effect of mineral additives on the structure and the physical- mechanical properties of gypsum stone}

On the schemes of the structure of gypsum stone with a filler, having a negative surface charge, shown in Fig. 3, $a, b$, the gypsum dihydrate crystals fit the surface of the filler grains with the longitudinal faces, forming electro-heterogeneous contacts with them. This is confirmed by EMI in Fig. 4, $e, f$. Such a filler in this work is granulated blast furnace slag. In the case of a rational ratio of the amount of gypsum and slag, there forms a fairly dense structure of the crystals of gypsum dihydrate, adjacent to each other at large angles and forming electro-heterogeneous contacts (Fig. 3,a). Mostly it is this mutual arrangement of crystalline hydrates that is seen on EMI in Fig. 4, $c-f$. However, in the center of the intergrain voids between the grains of slag one should expect the formation of pores ( $P_{0}$ in Fig. 3, $\left.a, b\right)$, reachable for water and for dissolving crystals from the ends. In the case of a deficiency of gypsum dihydrate, pores can form in the layers between the grains of the filler $\left(P_{1}\right.$ in Fig. 3, $b$ ), reducing the water resistance of the stone. Such round pores are seen on the EMI of the stone without a micro-filler in Fig. 4, $a, c$.

The correctness of the presented models, in addition to EMI, is also confirmed by the results of studying the dependence of the strength and water resistance of gypsum on the content of the filler such as slag (Fig. 5). The maximum water resistance indicators are observed in the $S /(G+S)=0.2-0.6$ slag content interval (depending on the water-solid ratio), which corresponds to the rational ratio of gypsum to slag and ensures the densest structure of the stone (Fig. 5, as well as [24]).

The introduction of a micro-filler with a negative surface charge (microsilica) [24] or the use of such a polyfraction filler leads to the filling of pores $P_{1}$ with their particles (Fig. 3,c), the reduced porosity, the increased water resistance. This is confirmed by the results of studying the dependence of the strength and water resistance of gypsum on the content of microsilica in it (Fig. 6,e). The chart shows that with the introduction of up to 0.035 of microsilica the water resistance ratio increases by $0.2-0.4$ units, from $0.5-0.6$ to $0.7-1.0$.

The introduction of a micro-filler with a positive surface charge (nano dispersed alumina) leads to filling the pores $P_{0}$ with its particles (Fig. 3, $d$ ), as well as the increased water resistance. This is confirmed by the smaller number of visible pores on the EMI of the gypsum stone with a filler and a micro-filler. In addition, the images show aggregates-spherulites from the crystals of gypsum dihydrate, which could form around the particles of the micro-filler as the centers of crystallization (Fig. 4, $d, f$ ). This is also confirmed by the results of studying the dependence of the strength and water resistance of gypsum on the content of nano dispersed alumina in it (Fig. 6, $f$ ). The dependence shows that with the introduction of up to 0.06 of nano dispersed alumina the water resistance ratio increases by 0.8 units, from 0.1 to 0.9 .

Our experimental results on increasing the gypsum water resistance by introducing mineral fillers such as slag (Fig. 5), microsilica, and nano dispersed alumina (Fig. 6) can be explained by the following. Their introduction into the gypsum mixture leads to the directional formation of gypsum stone structure. The structure-forming filler particles 
provide the formation of the structure of gypsum stone as a compositional material (Fig. 3) while micro-fillers ensure the filling of intergrain voids between the structure-forming particles with dense aggregates from gypsum dihydrate crystals (Fig. 3, c, d). A match between the schemes in Fig. 3 and the electron-microscopic images in Fig. 4 confirms the correctness of this representation. This structure is characterized by a large number of electro-heterogeneous contacts while the filler and micro-fillers together would provide the maximum protection of gypsum dihydrate crystals, especially their end faces, from contact with water and from dissolution.

Fillers and micro-fillers also contribute to changing the porous structure of artificial stone and reducing its porosity. First, their dense particles replace a part of the porous gypsum stone. Second, the electro-heterogeneous contacts of the lateral faces of gypsum dihydrate crystals with the surface of slag and microsilica particles contribute to the formation of dendrite-like structures from crystals, and the end faces of crystals with the surface of the nano-dispersed silica particles - spherulites, denser than the structure of gypsum stone without mineral fillers.

Thus, the mechanism of influence of mineral fillers such as ground granulated blast furnace slag, microsilica, and nano dispersed alumina on the structure formation of gypsum stone implies the formation of the structure of the compositional material, denser than that of the gypsum without additives, in which the crystals of gypsum dihydrate form with the filler particles water-resistant electro-heterogeneous contacts, and are maximally protected against the effect of water by them. A given mechanism applies to gypsum only. Its application to other air binders requires a new analysis of their morphology and electrosurface properties.

In other words, the issue of establishing the mechanism of influence exerted by mineral fillers and their electrosurface properties on the structure formation of gypsum stone has been resolved. Understanding this mechanism could improve the water resistance of construction gypsum by the introduction of a mineral polydisperse filler, which has a negative surface charge, in a combination with a micro-filler with a negative or positive surface charge. In this work, we used slag as a polydisperse filler with a negative surface charge in a combination with microsilica; we applied nano dispersed alumina as a micro-filler with a positive surface charge. Most current studies into the effect of additives on the physical-mechanical properties of gypsum stone do not take into consideration the electrosurface properties of structure-forming elements.

The most effective advancement of our work could be the research of gypsum stone structure-formation processes in the presence of filler additives with the established electrosurface properties.
The developed schemes and models of the gypsum stone structure with filler additives make it possible to reasonably approach determining the composition of the gypsum mixture. The proposed mechanism that forms the structure of gypsum stone with fillers and increases its water resistance makes it possible to develop the compositions for a mineral binder based on gypsum, which could be used in wet conditions of operation. This improvement in water resistance would significantly expand the application scope of mineral binders based on gypsum. This allows us to expect a significant effect in the industrial implementation.

\section{Conclusions}

1. We have modeled and devised the schemes of the structure of gypsum stone with the mineral filler and micro-fillers taking into consideration their surface charges. The adequacy of the developed schemes has been confirmed by the results of our optical-microscopic and electron-microscopic studies. It has been established that the increase in the water resistance of construction gypsum is possible through the introduction of a mineral filler with a negative surface charge and the micro-fillers with negative and positive surface charges. Such fillers ensure the formation of a dense structure of gypsum stone as a compositional material with a large number of electro-heterogeneous contacts, in which the gypsum dihydrate crystals are maximally protected from contact with water and from dissolution.

2. The results of our experimental study have established that the introduction of a mineral filler with a negative surface charge and the micro-fillers with the negative and positive surface charges ensures an increase in the strength of gypsum stone in a water-saturated state. The gypsum water resistance ratio increases to a value of 1 , that is, up to 0.8 units

\section{Acknowledgments}

We express gratitude to the founder of the scientific school, the Honorary Professor of the University, Arkady Nikolaevich Plugin, whose ideas about the role of electro-heterogeneous interactions in the hardening of mineral binders underlie our research. The current study was carried out as part of the research work "The theoretical and experimental fundamentals for determining, forecasting, and ensuring the load-carrying capacity and safety of transport facilities under conditions of aggressive influences", the State Registration Number 0119U100295, which is financed by the state budget.

\section{References}

1. Lushnikova, N., Dvorkin, L. (2016). Sustainability of gypsum products as a construction material. Sustainability of Construction Materials, 643-681. doi: https://doi.org/10.1016/b978-0-08-100370-1.00025-1

2. Petropavlovskaya, V., Buryanov, A., Novichenkova, T., Petropavlovskii, K. (2018). Gypsum composites reinforcement. IOP Conference Series: Materials Science and Engineering, 365, 032060. doi: https://doi.org/10.1088/1757-899x/365/3/032060

3. Fischer, H.-B., Vtorov, B. (2002). Zur charakterisierung historischer gipsm rtel. ZKG International, 55 (5), 92-99. Available at: http://wtorov.narod.ru/Publikaz/ZKG_2002_1/Histor-Putz.htm

4. Buryanov, A., Petropavlovskaya, V., Novichenkova, T. (2013). Structuring in Systems on the Basis of Calcium Sulfate Dihydrate. Applied Mechanics and Materials, 467, 91-96. doi: https://doi.org/10.4028/www.scientific.net/amm.467.91 
5. Wansom, S., Chintasongkro, P., Srijampan, W. (2019). Water resistant blended cements containing flue-gas desulfurization gypsum, Portland cement and fly ash for structural applications. Cement and Concrete Composites, 103, 134-148. doi: https://doi.org/ 10.1016/j.cemconcomp.2019.04.033

6. Zavadskaya, L. V., Berdov, G. I. (2016). Change of Structure and Strength of Gypsum at Adding Disperse Mineral Additives. Research Journal of Applied Sciences, Engineering and Technolog, 12 (1), 86-93. doi: https://doi.org/10.19026/rjaset.12.2306

7. Sun, H., Qian, J., Yang, Y., Fan, C., Yue, Y. (2020). Optimization of gypsum and slag contents in blended cement containing slag. Cement and Concrete Composites, 112, 103674. doi: https://doi.org/10.1016/j.cemconcomp.2020.103674

8. Egorova, A. D., Filippova, K. E. (2019). Ultra-disperse modifying zeolite-based additive for gypsum concretes. IOP Conference Series: Materials Science and Engineering, 687, 022030. doi: https://doi.org/10.1088/1757-899x/687/2/022030

9. Pervyshin, G. N., Yakovlev, G. I., Gordina, A. F., Keriene, J., Polyanskikh, I. S., Fischer, H.-B. et. al. (2017). Water-resistant Gypsum Compositions with Man-made Modifiers. Procedia Engineering, 172, 867-874. doi: https://doi.org/10.1016/j.proeng.2017.02.087

10. Yakovlev, G., Polyanskikh, I., Fedorova, G., Gordina, A., Buryanov, A. (2015). Anhydrite and Gypsum Compositions Modified with Ultrafine Man-Made Admixtures. Procedia Engineering, 108, 13-21. doi: https://doi.org/10.1016/j.proeng.2015.06.195

11. Sanytsky, M., Kropyvnytska, T., Fischer, H.-B., Kondratieva, N. (2019). Performance of Low Carbon Modified Composite Gypsum Binders with Increased Resistance. Chemistry \& Chemical Technology, 13 (4), 495-502. doi: https://doi.org/10.23939/ chcht13.04.495

12. Kondratieva, N., Barre, M., Goutenoire, F., Sanytsky, M. (2017). Study of modified gypsum binder. Construction and Building Materials, 149, 535-542. doi: https://doi.org/10.1016/j.conbuildmat.2017.05.140

13. Kondratieva, N., Barre, M., Goutenoire, F., Sanytsky, M., Rousseau, A. (2020). Effect of additives SiC on the hydration and the crystallization processes of gypsum. Construction and Building Materials, 235, 117479. doi: https://doi.org/10.1016/ j.conbuildmat.2019.117479

14. Suárez, F., Felipe-Sesé, L., Díaz, F. A., Gálvez, J. C., Alberti, M. G. (2020). On the fracture behaviour of fibre-reinforced gypsum using micro and macro polymer fibres. Construction and Building Materials, 244, 118347. doi: https://doi.org/10.1016/ j.conbuildmat.2020.118347

15. Plugin, A. N., Plugin, A. A., Kalinin, O. A., Miroshnichenko, S. V., Plugin, D. A., Kaganovskiy, A. S. et. al.; Plugin, A. N. (Red.) (2012). Osnovy teorii tverdeniya, prochnosti, razrusheniya i dolgovechnosti portlandtsementa, betona i konstruktsiy iz nih. Vol. 3. Teoriya prochnosti, razrusheniya i dolgovechnosti betona, zhelezobetona i konstruktsiy iz nih. Kyiv: Nauk. dumka, 288.

16. Plugin, A. N., Fisher, H.-B., Plugin, A. A., Rapina, K. A. (2010). Mehanizm strukturoobrazovaniya i degidratatsii gipsovyh vyazhushchih. Zb. nauk. prats' UkrDAZT, 115, 5-22.

17. Babushkin, V. I., Plugin, A. A., Kostyuk, T. A., Matvienko, V. A. (1999). Vliyanie aktivnyh poverhnostnyh tsentrov na prochnost' svezheotformovannyh melkozernistyh betonov. Naukovyi visnyk budivnytstva, $5,85-88$.

18. Chepurna, S., Borziak, O., Zubenko, S. (2019). Concretes, Modified by the Addition of High-Diffused Chalk, for Small Architectural Forms. Materials Science Forum, 968, 82-88. doi: https://doi.org/10.4028/www.scientific.net/msf.968.82

19. Ivashchyshyn, H., Sanytsky, M., Kropyvnytska, T., Rusyn, B. (2019). Study of low-emission multi-component cements with a high content of supplementary cementitious materials. Eastern-European Journal of Enterprise Technologies, 4 (6 (100)), 39-47. doi: https://doi.org/10.15587/1729-4061.2019.175472

20. Krivenko, P. V., Petropavlovskyi, O., Rudenko, I., Konstantynovskyi, O. P. (2019). The Influence of Complex Additive on Strength and Proper Deformations of Alkali-Activated Slag Cements. Materials Science Forum, 968, 13-19. doi: https://doi.org/10.4028/ www.scientific.net/msf.968.13

21. Danchenko, Y., Andronov, V., Sopov, V., Khmyrov, I., Khryapynskyy, A. (2018). Acid-basic surface properties of clay disperse fillers. MATEC Web of Conferences, 230, 03004. doi: https://doi.org/10.1051/matecconf/201823003004

22. Plugin, A. A., Pluhin, O. A., Borziak, O. S., Kaliuzhna, O. V. (2019). The Mechanism of a Penetrative Action for Portland CementBased Waterproofing Compositions. Lecture Notes in Civil Engineering, 34-41. doi: https://doi.org/10.1007/978-3-030-27011-7_5

23. Sopov, V., Pershina, L., Butskaya, L., Latorets, E., Makarenko, O. (2017). The role of chemical admixtures in the formation of the structure of cement stone. MATEC Web of Conferences, 116, 01018. doi: https://doi.org/10.1051/matecconf/201711601018

24. Plugin, A. A., Plugin, O. A., Fisher, H.-B., Shabanova, G. N. (2011). Increase of gypsum water resistance by mineral additives. Conference: 1 Weimarer Gipstagung, 435-443.

25. Plugin, A. A., Fisher, H.-B., Borziak, O. S., Iefimenko, A. S. (2017). Influence of mineral fillers on the processes of structural formation of gypsum stone. Naukovyi visnyk budivnytstva, 90 (4), 116-119. Available at: https://vestnik\%2Dconstruction.com.ua/ images/pdf/4_90_2017/22.pdf

26. Babushkin, V. I., Novikova, S. P. (1973). O roli kolloidno-himicheskih yavleniy v obemnyh izmeneniyah tsementnogo kamnya i betona. Tr. VNIIVODGEO. Moscow, 133-144.

27. Babushkin, V. I., Kondrashchenko, E. V., Kostyuk, T. A., Novikova, S. P. (2002). K voprosu o metodologii izmereniya elektropoverhnostnyh svoystv chastits v vyazhushchih sistemah. Budivelni materialy, vyroby ta sanitarna tekhnika, 17, 38-43. 